Article

\title{
Customizing Methodological Approaches in Qualitative Research on Vulnerable Children with Autism Spectrum Disorders
}

\author{
Pernille Skovbo Rasmussen ${ }^{1, *}$ and Anne Katrine Pagsberg ${ }^{2}$ \\ 1 VIVE - The Danish Center for Social Science Research, Copenhagen K 1052, Denmark \\ 2 Child and Adolescent Mental Health Centre, Mental Health Services Capital Region Copenhagen, University \\ of Copenhagen, Copenhagen DK-1165, Denmark; anne.katrine.pagsberg@regionh.dk \\ * Correspondence: pera@vive.dk
}

Received: 4 October 2019; Accepted: 5 November 2019; Published: 7 November 2019

\begin{abstract}
Children with autism spectrum disorders often suffer from poor school inclusion, loneliness, and poor quality of life. Suitable support options for overcoming these risks are lacking, partly because children's perspectives concerning their support needs are unknown. We need to improve the involvement of children in social research. However, involving children with autism in research is not always simple, and there is scant literature on qualitative methods for addressing challenges related to involving children with unique characteristics such as autism. Children with autism may lack mimetic expressions to reflect their feelings, and they may answer questions very briefly despite having a nuanced perspective on the issue addressed, thus leaving the researcher with few indicators to act upon. Consequently, it can be difficult for the researcher to "read" the child, assess ethical important moments, and adapt the methodology to the individual child. Based on a qualitative study of 22 children with autism in the capital region of Denmark, this article offers reflections on methodological and practical challenges in involving children with autism in research. Matching expectations between researcher and child, staying open to communication forms, and posing precise questions are shown to be important to have insight into the children's perspectives.
\end{abstract}

Keywords: qualitative method; children; autism spectrum disorders; methodological challenges

\section{Introduction}

Children are increasingly recognized as important agents in the research on children's everyday lives and wellbeing. Within the new sociology of childhood, children are not only viewed as "subordinates" to whom adults should speak but also as important social actors who should be involved and recognized as having legitimate voices of their own [1-4]. This sociological childhood agenda is in line with the requirements of the United Nations Convention on the Rights of the Child (UNCRC) (1989), prescribing that children have the right to express their views freely in matters affecting them. Children are essential receivers of social support, and this is why researchers demand increased recognition of children's own perspectives in organizing welfare services aimed toward children [5-8]. In line with this growing demand to involve children in societal planning, the literature on methods and ethics in research on children has expanded over the past decades [7,9-12].

However, there is a paucity of research and methodological literature describing how to involve vulnerable subgroups of children with unique characteristics, such as developmental disabilities including autism spectrum disorders (henceforth referred to as "autism"). An increasing number of children are diagnosed with autism. In fact, some studies estimate that the prevalence of autism among children has increased 20- or 30- fold since the 1970s [13]. These children constitute an 
exposed group in society that needs research attention in order to improve their well-being and educational development [1]. Nevertheless, the perspectives of children with autism are only presented in research to a limited extent [14,15], and the studies involving children with autism do not focus on the development of methodological, practical, and ethical learning.

Autism might influence the way that we as researchers should involve the child in our research for other reasons as well. For example, autism causes difficulties in social interaction, social communication, and social imagination, meaning that understanding indirect talk or hints, reading facial mimics, and imagining other people's thoughts and feelings can be difficult for individuals with autism, and communication in general, especially with strangers, can be a challenge for autistic people [16-18]. In qualitative research, interaction and communication are essential for gaining insight into the unique perspectives of individuals, and autism is naturally challenging in relation to participating in qualitative research.

In addition, autism is often, but not always, correlated with a high risk of psychiatric comorbidity, such as depression or anxiety [19-21], as well as poor school and educational performance, loneliness, poor social inclusion with peers, and poor quality of life [20,21]. For these reasons, children with autism can be vulnerable and difficult to include in research. Examining the school well-being and everyday lives of children with autism is a delicate process, as the topics might be sensitive for the child. Moreover, while school well-being can be a sensitive subject for children without autism, the challenges are enhanced due to their inherent communicative difficulties as well as difficulties in "reading the social game", that is, imagining other children's emotions and talking about abstract concepts. Children with autism can be viewed as a unique group that requires, if not reinterpretation, then adaptation, adjustment, or customizing of the qualitative methods typically used for research purposes, which is the focus of this article.

Neither autism nor childhood is considered a fixed concept; rather, they are sociocultural flexible categories [22] associated with overall understandings that are constantly being developed in line with societal approaches to health, childhood, and normality [23]. This might explain why there seem to be very few studies that link qualitative research methodology with childhood research as well as with autism research. Indeed, there is virtually no literature examining methods and practices for involving children with autism in qualitative research [6,24]. Consequently, this article set out to explain the methodological and practical knowledge gained from a qualitative study conducted with 22 school-aged children with autism, living in the capital region of Denmark. The overall purpose of this article is to encourage more research on the everyday lives and well-being of children with autism, as demanded by researchers in the field $[5,14,15]$, by sharing methodological learnings.

\section{Methods and Empirical Data}

The qualitative study of 22 children represented in this article is part of a larger mixed-method research project on the everyday lives and school experiences of 65 children with autism. The results concerning the children's school well-being and everyday lives are reported elsewhere (first author), whereas this article will focus on the methodological and practical knowledge gained. The conduct of the study is based on the first author's experience working with children and adolescents with autism in institutions and school settings (more than 10 years), which provides a broad insight into how children with autism can be viewed as a unique group for qualitative research purposes. Furthermore, this study is based on experiences gained from spending one month observing diagnostic processes in outpatient clinics of the Mental Health Services in the Capital Region of Denmark. These experiences with autism pedagogy and autism diagnostic processes mean that the children have been met with a professional knowledge of their possible challenges, but, at the same time, they have been met with an openness and ignorance of their specific personal living conditions. The absence of in-depth knowledge of the specific children in the study has increased the opportunities for the children to provide their own perspectives on everyday life and school well-being. In line with Parsons [14] and 
Preece and Jordan [15], it is our experience that children with autism would like to be included in research concerning their daily lives, and this is what motivated this study.

\subsection{Participants and Recruitment}

The 22 children who took part in the qualitative study were 9-15 years of age and had all undergone a diagnostic process in outpatient clinics in the Capital Region of Denmark and received an autism diagnosis prior to the study. They were all mild to moderately influenced by their autism, meaning that they had understandable language and could engage in the ordinary school environment to some extent, possibly with personal teacher support. Some of the children had a concurrent diagnosis such as anxiety (6/22 children) or attention deficit hyperactivity disorders (7/22 children); however, autism currently posed the most significant challenge for all of the children in this study though in slightly different ways. While some children had difficulties with making inappropriate comments or showing a lack of empathy in various situations, other children had difficulties with abstract and hypothetical thinking, or in sharing peers' interests, or challenges due to sensory sensitivity. All children in the study had different challenges in several areas of the autism spectrum. About half of the children (12/22 children) had an Asperger's diagnosis within the autism spectrum while the remaining children had various other forms of autism disorders. They were all diagnosed according to the ICD-10, which is the classification system commonly used in a Danish clinical context.

Ten of the 22 children were recruited for face-to-face interviews through the outpatient clinics by the end of their diagnostic process. The recruitment was based on a strategic selection aiming at diversity in the participant group in terms of age and gender. By interviewing the children singly, the possibilities for individual adaptation of the conversation with the child and for deepening the understanding of the child's perspectives are optimized.

Twelve other children were included in the study through repeated informal conversations conducted in the Center for Autism Denmark (CAD), where the first author spent six months conducting participant observations in two network groups, one each for girls and boys. Participation in the groups made it possible to get closer to the children in more informal settings and situations. The purpose of the network groups was to enable the children to meet their peers with autism, share experiences, and practice social skills. The group meetings were held one evening per week and included dining together as well as various activities, such as playing cards, board games, table tennis, billiards, painting, drawing, or engaging in other creative pursuits. Most of the children in the two groups ( 7 out of 12 in the boys' group and 5 out of 8 in the girls' group) repeatedly took the initiative to converse with the first author during the group meetings, either alone or in pairs. In contrast, the rest of the children in the groups either scarcely communicated in general or did not show much interest in the research purposes despite being invited to share their perspectives during the meetings; therefore, they are not mentioned in this article.

\subsection{Procedure and Researcher Role}

The first author conducted the ten interviews in each child's home, as recommended in the childhood research literature, which highlights that a safe environment for the child facilitates a more confidential conversation $[10,25,26]$. Prior to interviewing the children singly, their parents (or one of them) were interviewed to make both parents and children comfortable with the child interview and to prepare the first author for the meeting with the child, as also recommended in other studies involving children $[25,27]$. Both the children and their parents received written and oral information about the study; both types of information were adapted in each situation to fit the child's age and school level. All children were told that answering questions was voluntarily and that they could withdraw from the study at any time without being asked for explanations, but none of them chose to do so.

Prior to the participation study in the network groups at CAD, all implicated children and their parents received written information about the study and were advised about the possibility to opt out of participation (no one elected to opt out). Additionally, I (the first author) introduced myself 
and the purpose of the study orally at the beginning of the study and throughout the six months in the two network groups. During my repeated informal conversations with the children and young people in the groups, I struck a delicate balance between not becoming too close to the children (as to leave them with the feeling of becoming close friends) and being close enough to gain their confidence and enable open conversations with them. I purposely shifted conversational partners during the evenings and did not allow one child to feel chosen over the others while being open and approachable to all children during the meetings. During informal conversations as well as in the interview situations, I tried not to assume "a teacher role" or portray myself as a "young person" like themselves (see also [10] p. 255 discussing researcher roles as "least adult" roles). Instead, I followed my own open-minded and friendly approach, which involved being present and respectful without being intrusive. During conversations, I tried to use the children's own wordings and to test my understandings of the children's perspectives by asking the children to elaborate on their answers and by presenting my understandings of their statements; sometimes, the children would correct me, in other cases they agreed.

\subsection{Ethical Approach}

The study has been based on a situational ethical perspective [28,29], implying a moral obligation to listen respectfully to the children and making it a priority to ensure that all conversations were considered comfortable for the children so that they had positive feelings about their ability to contribute. Children are not necessarily always self-aware of what they think and feel and what their own perspectives are until researchers try to formulate them in cooperation with the children. In other words, children's perspectives are dynamic constructions created in their interactions with the researcher [10,30-33]. Accordingly, my interviews and conversations were based on my conscious attempts to position the children actively in the knowledge construction. For instance, I encouraged them to choose conversation themes and to control their pace in the conversations as much as possible. As Prout [34] noted, the inclusion of children's voices in research "has added new complexities and uncertainties to the research process" [34] (p. 482), and so I attempted to be both humble and cautious in managing the conversations with the children in addition to obtaining their informed consent to participate. Obtaining informed consent is not a single act, but rather a process that should be repeated throughout the research [35]. Thus, I frequently mentioned my purpose of being present and sometimes reminded the children that they could end our conversation whenever needed. Ethics in qualitative research with children is a dynamic process that is constantly shaped and reshaped throughout the process, and it is influenced by streams of "new values" in the ethnographic discipline [36]. The researcher should accept all researched subjects as social actors and "respect them and protect them equally" [36] (p. 205), whether being a child or an adult, female or male, illiterate or literate, etc.

For the sake of confidentiality, personally identifying information has been removed, and all names cited in this article are fictive. The study has been approved by the National Data Protection Agency (Journal No. 2012-58-0004) and the Local Ethics Committee (Protocol No. H-16017801) and has observed the rules of the Declaration of Helsinki of 1975.

\subsection{Methodological Approach}

While ethical principles should remain the same for all individuals since all people have the same ethical rights despite age, gender, ethnicity, and social background, as stated by Tulebaeva [36] (p. 204), methodologies should vary, and the approaches to participants and ways of gaining insights into the participants' perspectives should be adjusted as needed. Some researchers in the field of childhood studies emphasize that children are competent and therefore should be treated no differently from adults when involving them in research [37] (p. 165). However, a review of methodological issues in conducting qualitative research involving children concludes that there are differences between studies involving children and those involving adults. For example, power relations are by nature unequal when adults conduct research involving children [38]; likewise, there are inherent 
disparities in cognitive development, communication skill levels, and worldviews of children and adults [10] (p. 1258). For these reasons, my methodological starting point has been based on commonly accepted standards for research involving children, which are different from those involving adult participants $[9-11,25,38]$. These standards prescribe, for instance, how the researcher should consider the design of the research settings and tools, including the questions posed and language used, as children, like adults, can be sensitive towards leading or biased questions [7,10-12]. The scope and content of the interviews and informal conversations in this study were adjusted depending on the child's readiness to talk about different matters of everyday life and their individual interests, experiences, and challenges in school and home affairs.

The methodological approach in this study was based on the knowledge that children's autism might cause them difficulties in social interaction and communication [16-18,39]. Hence, each child has been involved according to her or his individual preferences concerning communication framings (sitting, walking, playing in while talking, etc.), language use, thematic focus, and duration of the conversation. However, customizing qualitative research to each specific child is challenging for many reasons. I cannot read the children's minds concerning their preferences during the interview, and I do not always recognize their bodily signals since I do not know them well enough and because body language can be limited by autism. This article shares our learnings and practices as well as ethical considerations related to this process of involving children with autism in research.

Since there were few existing studies to lean upon in the methodological planning of this qualitative study, many questions arose prior to the qualitative data collection: What are the criteria for successful involvement? When is sufficient involvement of children in research achieved? How is a study planned considering the fact that children are very differently challenged in terms of social interaction and communication? While some children with autism lack mimicry, gestures, and eye contact, other children with autism are very lively in terms of body language and expression, although they may have difficulty thinking hypothetically or understanding their own feelings as well as difficulties answering open questions. In this study, we operated with both a semi-structured interview guide and an open interview guide, which were applied or even mixed as needed. In addition, pictograms, which are simple pictures of school and everyday situations, were introduced in some of the interviews to initiate and stimulate an open dialogue with the children. These different approaches and methodological experiences using them will be discussed further in this article.

\subsection{Data Analysis}

Notes from informal conversations were made partly during and partly immediately after each group meeting, and all interviews were recorded and transcribed verbatim. Notes were also made at the end of each interview, concerning what went well or not well in involving the child in the study, what the atmosphere was like during the conversations, and an impression of the child's openness to actively participate. Inspired by interpretative phenomenological analysis [40,41], transcripts and notes were read and re-read thoroughly and the first impression of the methodological attention points were noted. Subsequently, exploratory notes on the data were made, and interpretative conceptual questions about the findings were asked and discussed by the authors: What challenges did I face in the conversations? When did the conversations succeed in having the child address everyday life matters? What methods or approaches seemed useful or not useful with this child group? What type of questions and researcher roles motivated the children to talk?

During the analysis, we examined what happened in the communication with the children prior to their unfolding of their perspectives or demonstrating the opposite behavior by keeping quiet or not responding. A conversation depends on at least two actors, which is why in this study it was assumed that the interviewer (first author) was crucial for motivating a response from the child and creating an open conversation. We tried to "... understand what it is like, from the point of view of the participants, to take their side", as recommended by Smith and Osborn [42] (p. 53), and to "... find out how individuals are perceiving the situations they are facing, how they are making sense 
of their personal and social world" [42] (p. 55). At the same time, we also tried to "... ask critical questions of the texts from participants, such as the following: What is the person trying to explain? Is something leaking out here that wasn't intended? Do I have a sense of something going on here that maybe the participants themselves are less aware of?", as Smith and Osborn recommend [42] (p. 53). In the analysis, we looked for factors that might have influenced the insights gained from the children, and we also examined situations in which involvement of the children seemed to succeed or fail, respectively. Looking across the themes emerging from transcripts and notes, some overall methodological and practical themes could be clustered as illustrated in Figure 1. The themes will be unfolded in the Findings section.

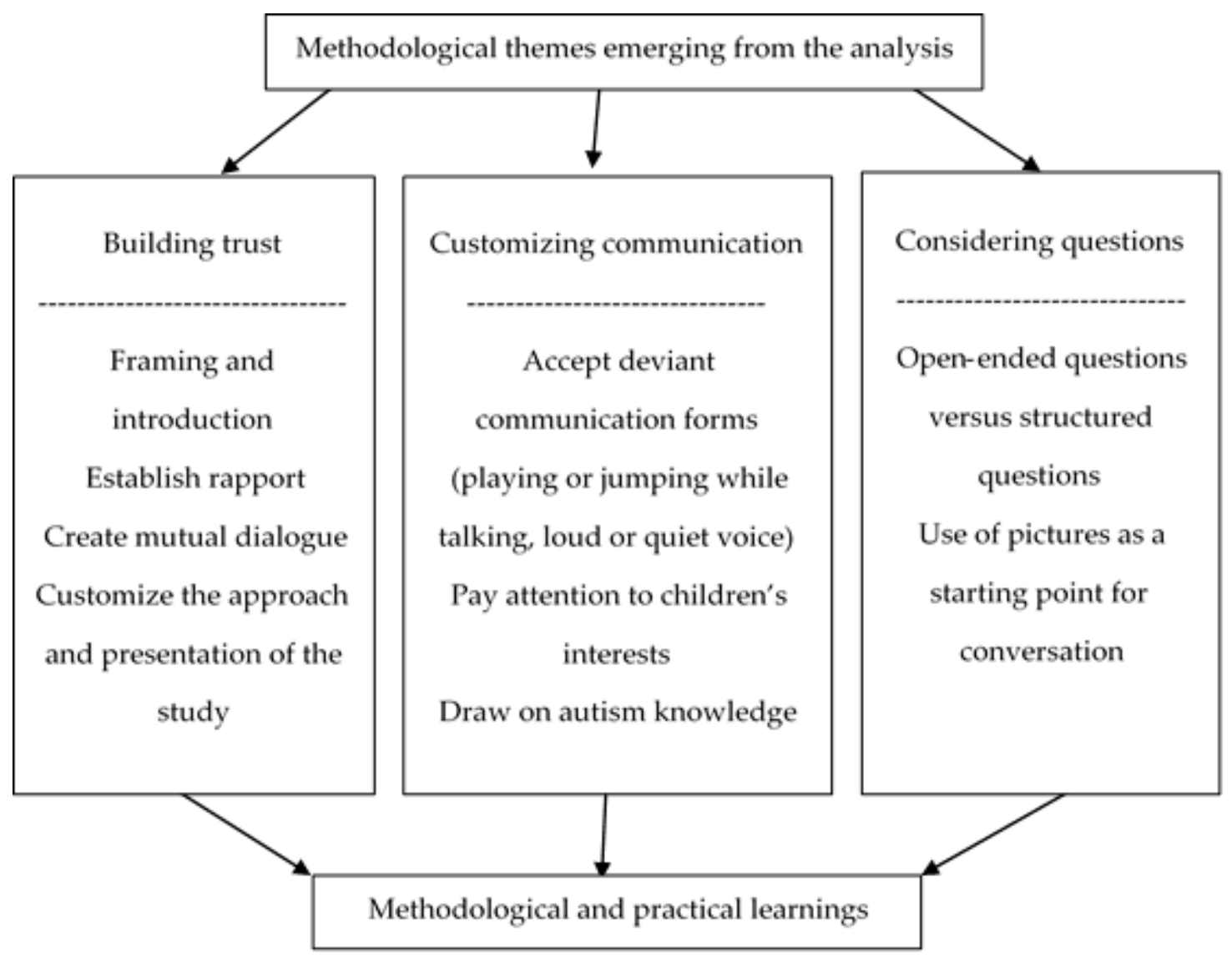

Figure 1. Themes from the analysis.

\section{Findings: Methodological and Practical Learnings}

We will begin the presentation of the study findings and learnings with two examples illustrating some of the methodological and practical challenges experienced in this study involving children with autism:

[Notes from an interview] In my interview with 13-year-old Elias, I had a hard time encouraging him to say more than monosyllables. Elias speaks in a monotone and a low voice and avoids eye contact, leaving me with the impression that he is not very comfortable with or not interested in sharing his perspectives on matters of everyday life with me, which is why I finished the interview early. However, the next day, Elias' mother wrote me an e-mail indicating that he enjoyed the interview and would like to participate again soon.

[Notes from a second interview] In my interview with 10-year-old Albert, I elaborated on the text of the information letter prior to the interview in the hope of facilitating a "mutual conversation" with Albert, inspiring him to talk. The letter also described my desire to hear about Albert's interests, 
not just about his school and family or friends. When I arrived at Albert's house, he was in his room, lining up role-playing swords to show me, and I barely had time to introduce myself before he began to tell me all about role-play, weapons, shields, armor, characters, and where to play. His voice gradually became louder, and he ended up almost shouting eagerly about role-play while he jumped around and imitated a fight with his sword. Though I sometimes interrupted with simple questions about school, family, and friends in an attempt to lead the conversation in other directions, Albert simply disregarded my questions or gave short answers and then continued to talk about role-play.

The examples show in different ways the overall key aspects or themes found in the analysis (see Figure 1) that are particularly important to consider methodologically when involving children with autism in qualitative research:

- building trust with the child and customizing the presentation of the interview purpose;

- customizing communication and being prepared for alternative conversation forms and topics;

- considering questions carefully in terms of being closed versus open-ended.

These overall analytical themes are in many ways also relevant to research with children in general (and sometimes adults too); however, this study shows that autism reinforces the need for attention to these points. We will return to the question upon the findings being relevant to research with children in general in the Limitations section.

\subsection{Building Trust and Customizing Preparations}

The preparation of each child was considered relevant prior to the interviews because autism often causes a weak theory of mind, meaning that it could be difficult to imagine an interview scenario and prescribe a strong need for predictability and preparation $[16,18]$. Accordingly, the preparation regarding the time, place, duration, focus, and purpose of the interview as well as the child's right to interrupt at any time, if desired, was written in an information letter, designed individually, and based on the parents' information about the child. If the parents reported that the child was having difficulties in school and generally did not enjoy talking about school, then school was not mentioned in the letter. The intention was to create a positive approach to the child and the interview. In addition, the parents cooperated in preparing the interviews with the children by making agreements in advance with them about where the interview should take place, whether a parent should be present (one child chose so), and whether the child would like to do any specific activity, such as drawing or puzzles, while talking (most of the children chose to). As such, the parents became both important gatekeepers and co-workers (as also described in $[25,27]$ ) in the oral preparation together with the child. In some cases, the preparation work paid off in the sense that some preliminary maneuvers during the interview were skipped and the children seemed confident about the situation. Consequently, some of the interviews started quickly, as in the following example with nine-year-old Asta, who almost corrected the interviewer concerning the purpose of the interview:

[Notes from an interview: I have just arrived in the family kitchen, where Asta prefers to talk. Asta's mother moves to the living room and closes the door. I introduce the study.]

Me: I would really appreciate it if you could help me by telling me about yourself and how you spend your time. I can see that you are wearing a t-shirt with horses; do you like horses?

Asta: You forget to say that you would also like to hear about friends and school; you wrote that in the letter.

Me: That is right. Would you like to tell me about your friends and school? Where do you go to school?

Asta: [tells me the name of the school, the school address, how to get there, and which class and specific building she is in] ... but my parents are trying to get me into another school, so I do not know for how long...

Me: Okay.

Asta: ... and if you want to hear about friends, I have one friend, and she is on holiday right now ... 
In the case of Asta, the preparation seemed to succeed in having her tuned in to the purpose of the interview, thereby opening up the possibility of my asking further questions concerning the topics of school and friends, which she mentioned herself. In contrast, in other interview situations, the preparation caused the child to overdo it, as in Albert's case (introduced in the example in the beginning of the finding section). Albert almost prepared a full speech beforehand about the discipline of role-playing. He had taken my introduction letter quite literally, mentioning that "I would like to hear about your interests and leisure activities" among other quotes. This example illustrates a potential pitfall in preparing the child for the interview: the risk that it could be a "failed interview" [43] (p. 717) in the sense of not providing knowledge "on the research agenda" or only providing limited knowledge. If the preparation, including the introduction letter, is too unfocused, inviting the child to talk about whatever he or she wants to, the researchers' risk receiving unfocused information from the children rather than specific insights into their perspectives on their well-being and school inclusion as intended. The child (with autism) often has difficulties in deviating from what he or she assumes to be the planned conversational topic and in catching the conversation partner's hints to change topics during the talk.

Another risk is "a silent interview," as in the case of Elias (presented at the beginning of the findings section), who used few words and avoided eye contact, at least in the first part of the interview. It is difficult to infer from the situations if such "silent interviews" are due to incomplete information and preparation about what an interview is about, the child's communicative challenges, or the researcher's inability to motivate the child to engage in mutual conversation. Since Elias mentioned to his mother after the interview that he would like to participate in the study again sometime soon, his case might illustrate how some children (with autism, as well as in general) need more time to become comfortable and develop rapport with the researcher [44,45]. It is commonly advised in the literature that the researcher should build the child's trust and help him or her to relax and feel comfortable with the situation. Rapport cannot be developed by an introduction letter or an oral preparation talk from the parents; it is a process that takes time $[10,11,30,33]$, particularly with children with autism.

By spending time with the network groups at the CAD, I experienced how some children needed time before interacting with me, whereas other children were curious and outgoing from the beginning. Moreover, while I was constantly aware of making contact with the children, I did this from a distance to allow them to feel free to reject or approach me on their own initiative. Overall, it was easier to develop rapport with the children in the network groups compared with the interview situations (see also Greig \& Taylor [44] and Wilson \& Powel [45], who recommend spending time with children to build rapport), in part because I had more time to let the children get to know me. Developing this kind of rapport, that is, reciprocity and mutual trust, was effective in engaging the children in the research and making them share their perspectives promptly and spontaneously. Spending time with the children in the network groups for six months made it possible to meet them in more informal settings, resulting in unprepared conversation topics presented by the children themselves and providing unique insights into their perspectives. As the following extract from a spontaneous conversation illustrates, the children's reflections, which could be difficult to predict before the interview, can occur spontaneously:

[Fourteen-year-old Tobias and I talk while preparing dinner together for the rest of the group.]

Me: Are you looking forward to the weekend?

Tobias: I hate [the] weekend; my mother just destroyed the idea of [a] weekend. She just suddenly without warning said this morning, "On the weekend, we are going to Jutland to visit your uncle." She knows that I have a complete meltdown when faced with such unforeseen things.

Me: ... and have you reminded her how you feel about that?

Tobias: No, because I know the answer. She just says that it is a good learning [experience] for me to not always plan everything, but she cannot see how I feel inside; I am burning. That is also why I started to pinch myself. Look, my arm is all red ( ... . . My mother doesn't know anything about how I feel; she understands nothing. 
The intimate forum of being alone with Tobias while occupied by a common activity and not having to talk face to face supported Tobias' liberated and spontaneous expressions based on his original reasoning (as demanded by Piaget [31]), not just random answers in an attempt to satisfy the researcher. Such personal sharing of the children themselves took time and mutual trust and primarily occurred some months into my participant observations at the CAD. Furthermore, insights into the children's perspectives often emerged from more confident situations, such as when I drove 13-year-old Eric home after a network meeting. During our moments alone in the car, having known each other for some months by that time, Eric shared his feelings of discomfort about attending the local mainstream school, as he was the only one in class with autism:

Me [chatting while driving the car]: So, what about the new class? Do you like this class better?

Eric: I hate my class; every day is a fight to survive bullying. I do not know why it is like that, but it is ... . It is hard to fit in their [classmates'] universe to perfection and with precision, not to say impossible, since I do not share their views and interests.

Eric also expressed his desires and dream of being a chemical engineer, leaving me with the impression of having gained insights into his perspectives on his everyday struggles with autism and with coping in a mainstream school.

Some of the children's personal sharing demanded ethical considerations, not least in cases where the children reported severe loneliness, experiences with bullying, violence, or drug experimentation. In these situations, I asked the children if they had someone to talk to about their situations, a teacher or a parent for instance, and in some incidences I talked to the network teacher confidentially about the issues that the children were dealing with, which she was always aware about already.

\subsection{Customizing Communication with the Specific Child}

Pramling [46] states that it is the researcher's responsibility to engage the child in conversations by addressing topics that the child has an interest in as well as to "create a trustful contact with the child, for without the child's engagement and willingness to work together with us we cannot learn anything from him/her" [46] (p. 26). Other more recent studies stress the importance of the researcher's self-preparation $[27,39]$ in relation to gaining insights into the child's everyday life through the child's own mediated perspective. Thus, childhood researchers emphasize that questions should be planned in accordance with the child's age and cognitive level, interests, capabilities, and willingness to talk about certain topics. I found that preparation regarding interview topics and ways of addressing the themes was not always a simple task in terms of having the child with autism participate in conversations in the best possible way. In many cases, thorough preparation was necessary in relation to the children's autism and possible challenges as well as to their individual interests. For instance, I found it advantageous when approaching the children in interview situations to have basic knowledge about their personal interests and their daily living conditions in order to meet them on their level.

Children with autism sometimes have special interests that can differ from those of their peers, such as a fascination with trains, computer programming, Japanese manga comics, advanced mathematics or chemistry, famous movie scenes, and cars or trucks (a boy I met in this study even knew all about moped engines). Without preparation, it can be difficult to build conversations around some topics concerning the children's interests. Therefore, having an idea about these interests can be advantageous during the interview or informal talk. It can serve as an icebreaker, opening the dialogue by talking about something that the child enjoys. It can also allow the researcher to gain a quicker understanding of the child's reference point, such as when mentioning names from Japanese comics during the interview or when reconstructing a scene from a movie, as 13-year-old Jacob did in an informal conversation. Here, he is citing a scene from Lord of The Rings (a character in the film that is wavering between good and evil, with each aspect having a nickname):

Jacob: ... so when she [his mother] says that I cannot play anymore [computer games], she does not know how it is like. "Gollum needs his precious" right, but "Sméagol says no, but Gollum needs" .... You know, sometimes, gaming is the only way that I can relax ... . 
I experienced the pitfall of not knowing anything about the child's interests in the case of Peter, a 14-year-old boy at the CAD, who knew all about a certain computer game and "live[d] his parallel life in this game," as mentioned by one of his peers. Peter made some initial attempts to converse with me during the network meetings, but I often fell short in truly engaging with his invitations since he was absorbed by his gaming world, which he spoke a lot about. My inadequacy was due to my lack of knowledge about the specific game universe. Thus, it seemed that I was never really able to offer anything in a mutual conversation with Peter, apart from being a passive listener. Sometimes, it seemed sufficient for Peter that I was willing to listen to his detailed explanations about the computer game, thereby serving as an "acting apprentice" in his universe [38], and Peter would continue to talk for a long time. In other situations, Peter sought others to share his gaming experiences that could interact more actively with him and understand his parallel world better.

Furthermore, I found that preparation related to the child's individual challenges or vulnerabilities was important in some cases in order to involve him or her ethically and comfortably. Most of the children in this study were newly diagnosed, and half of them were exhibiting depression, ADHD, or anxiety symptoms as well. Some parents claimed that their children would probably withdraw if I mentioned autism or other diagnoses because they had not yet become familiar with or accepted their diagnoses. In other cases, the child had not yet been made aware of the autism diagnosis by parental choice to prevent the child from feeling labeled or disabled; these children only knew they were having challenges but not that there was a name for these challenges. Accordingly, I avoided confronting or mentioning autism in the interviews. However, it occasionally happened that the child him- or herself talked about autism or these unlabeled challenges, showing how the pre-impression of the child, given by the parents, could pose a potential risk (as well as certain advantages) since the researcher might limit the conversations unnecessarily. In other situations, preparation concerning the child's individual challenges or vulnerabilities was shown to be important. For instance, Jacob's parents told me about his severe difficulties in making friends in school, which I took into account in the interview by not assuming that all children had friends in school; thus, I approached the subject carefully. Learning from previous studies (e.g., [33,37]), I found it useful in some interviews to bring up sensitive topics by relating what other children had said about being challenged in school or not knowing how to make friends, thereby making it easier for the child to share such experiences. This technique seemed to work with some of the children, whereas others obviously could not relate to a story about someone they did not know. Autism often causes difficulties in mentalizing and hypothetical thinking, and that can probably explain why only some conversations benefit from the technique of citing examples.

Conducting research on children with autism demands "bracketing" or "setting aside" assumptions and beliefs [38] about childhood in order to avoid presuming that all children have friends or enjoy school and typical interests, such as sports. Moreover, researchers need to "bracket" their preconceived notions about conventional ways of communicating when studying children with autism. This study has shown that knowledge about autism is important for understanding and handling situations when children either talk loudly or are very quiet, come very close to the interviewer's face during conversations (one almost sat on my lap), or show limited or inappropriate facial expressions. It is also essential to be prepared for alternative conversation forms, such as children preferring to spin around while being interviewed, doing puzzles, or working with a Polybius square while talking and thus making minimal eye contact. However, reading other people's body language in mutual communication is so deeply embedded in most of us that deviations from our communicative instincts are quite demanding. In Elias' case (as presented in the examples in findings section), I was keenly aware of the potential symptoms of autism but still failed to rely on this knowledge in my understanding of the situation, misinterpreting his (lack of) facial mimicry, quiet talk, and few words as lack of enthusiasm.

\subsection{Structured versus Open-Ended Approaches}

Some qualitative researchers claim that information obtained from free recall, also called an unstructured or open interview, is more likely to capture the unique perspective of children, as opposed 
to receiving responses to questions from the perspectives of adults [7,30,33,47]. In a study comparing structured and unstructured interviews with children (without autism), Steward and Steward [48] found that open interviews allowing the children to speak more freely yielded more in-depth information. Consequently, the authors advised interviewers to begin with an open-ended question to elicit a spontaneous narrative and then ask direct questions to fill in the blanks in that narrative. However, they also concluded that some children with poor language and communication skills found the task of free recall more frustrating and tiring compared to a more direct approach. In this study, I found that letting the children "warm up" with easy, structured, and simple questions was often advantageous, as also reported by Irwin and Johnson [25] in their study on young children. In this study, some children needed more encouragement and structured questions to start talking. When they felt comfortable with the situation, they were then able to handle more open-ended questions and contribute with their own perspectives, expressing liberated and spontaneous convictions, as illustrated by the following excerpt from a planned interview with 13-year-old Nanna:

Entering the living room, I find Nanna doing puzzles at an amazing speed, with 1000 pieces filling the entire table where she is seated. She glances up shortly and vaguely says "hello" without making any facial expressions. Her mother tells me that Nanna had been looking forward to the interview. I introduce the purpose of my presence and thank her for allowing me to visit her. After a few more sentences, I start asking Nanna if she does many puzzles. Nanna says "yes." I proceed by asking her if she has interests other than doing puzzles. After a pause long enough for me to consider it difficult to get Nanna talking, she says two words: "music videos." She continues to gaze at her puzzle and put the pieces together. I change the subject by asking her about school but receive only short answers. I return to the topic about music videos and ask what types of videos Nanna likes, trying to motivate and engage her to use more words. As soon as I get Nanna to tell me about music videos, she uses many more words and explains, "Making the videos myself on YouTube makes me forget about my anxiety, and I totally forget about time and place".

When the agreed 25 minutes is over, I take the initiative to end the conversation by thanking Nanna and confirming how useful her participation has been. Almost interrupting, Nanna replies by telling me about one of her teachers: "Once, we had an English teacher who told me that I should control my anxiety, and I tried to tell him that it is really hard to control because if it was that easily done, no one would have anxiety ... . But he just told me to stop feeling that way, and that I am a bright girl that could do so".

The conversation continued for a while. Every time I attempted to end it out of respect for the agreed-on duration of the appointment, Nanna continued talking, presumably because she had been motivated to talk, although it initially took a long time to obtain her engagement, build rapport, and gain her trust.

It could be argued that structured questions lead the children towards certain answers instead of inviting liberated or spontaneous expressions [30,31]. Nonetheless, in many of the interviews precise and limited questions were necessary to get the child to talk at all and to align with the research areas of interest, as shown in the following excerpt from an interview with 13-year-old Elias:

Me: How about school-is there a subject in school that you particularly like?

Elias: [long pause] I'm not sure what you mean; uhmm, if I like a subject, is it the teacher you mean, or the books, or what we do in the subjects? How do you mean like the subject? I do not understand ...

Later in the interview, I asked Elias whether there were school subjects in which he was particularly clever. He replied, "I'm not sure I am the right person to answer that question; to be sure, you should ask my teacher." The precise question in this case would have been whether Elias himself believed he managed well in some subjects or if he found some subjects easy to learn. During another interview, I asked 11-year-old Victor if he found any particular subjects in school interesting, and he replied, "domestic science," and we talked for a while about this subject. Later in the interview, it became clear 
that Viktor would not have domestic science in school until two years later, but the question that I posed was not specific enough to capture this fact, as I only asked what he found interesting.

In the CAD network groups, the need for precision and structured questions was further observed. During an informal conversation with five of the 10-14-year-old girls, a YouTube video was shown by the teacher responsible for the group in order to start a debate on situations in which they should or should not tell others about their diagnosis. When the video was finished, the teacher asked, "What did this video show you?" One of the girls remarked, "The second time they were filming in the restaurant, the fork was in another position than the first time. I think that was a mistake." Another girl added that the tablecloth resembled one that her grandmother had. The girls were concerned with certain detached details in the video and obviously did not pay as much attention to the big picture or the message conveyed in the videos. Helping the girls focus on a concrete question about the message in the video then enabled them to contribute with their own perspectives on "who to share that you have autism with"; they just needed specific guidance.

Finally, this study showed how open-ended questions could still be difficult despite being accompanied by visual aids, such as pictograms or simple drawings of a school, home, or family, as recommended in some contexts when studying children with autism (see, e.g., [49]). In this study, the use of visual aids was tested in some of the interviews, but we found some inherent challenges, as the pictures were not individually suited to each child. As 10-year-old Alfred commented, "I do not know these cards. I only know some other cards we have in school, and they look different, so I cannot speak about the ones you have." The other children simply looked at the picture cards that I presented without responding or just answered "no" when asked to talk about the cards. Obviously, the pictograms that were unknown to the children did not encourage conversation or make them elaborate more on their everyday lives and well-being; rather, they seemed to annoy or confuse them.

\subsection{Limitations of the Study}

This study provides insights into how 22 school-aged children with autism, in given contexts (interviews or group-evenings) respond to given methodological approaches, undertaken by a given researcher. Thereby, the study is not comprehensively providing insights into how school-aged children with autism in general interact in qualitative research. Only school-aged children who are mild or moderately influenced by their autism were included in this study, and it is unknown whether the findings are valid for other groups of children with autism. Likewise, it is unknown to what extent the findings are valid for children without autism. Literature within methodology in childhood studies indicates that children in general are sensitive towards building trust with the researcher, and that some flexibility concerning interview form and topics are needed, particularly when researching with younger children. However, children without autism are in general described in methodological literature as being less sensitive towards open-ended questions and towards the preparation prior to the interview or conversation. We believe that this study illustrates methodological and practical attention points that are particularly important when studying with children with autism. However, more research is needed to decide which methodological customizations are needed for different subgroups of children. In time, it will be possible for subsequent studies to be conducted with other samples of children with autism, and, gradually, more general claims can be made about methodology in relation to children with autism.

Furthermore, a limitation in this study concerns the use of methodological approaches (interviews and informal conversations). Qualitative approaches such as diaries, videos and focus group interviews have not been examined in this study. Further research is recommended concerning the use of different qualitative approaches.

\section{Conclusions}

Qualitative research involving children in general, and especially with children with autism, can be challenging, unpredictable, and uncontrollable and can make it difficult for the interviewer to 
use standard interviewing principles $[10,25,30]$. It is not always easy to gain fully informed consent from a child, to compose information letters targeting a child prior to an interview, or to ensure common expectations for the interview between the researcher and the child. Furthermore, it is not always easy to initiate an open and spontaneous dialogue with the child, to encourage him or her in a natural way to address the research subjects that the researcher has a particular interest in, or to read and interpret his or her signals (e.g., body language) during the interview. This is especially true when the child has an autism spectrum disorder, which often involves challenges in social communication and social interaction.

In this article, we have reported methodological experiences in involving children with autism in qualitative research regarding their everyday lives and well-being. Children with autism are often represented by parents or teachers, and thus their individual voices and perspectives are excluded from research participation, partly due to the lack of research knowledge on how to involve this group of children. The young participants in this study have shown that it is both relevant and methodologically possible to involve children with autism in qualitative research (as also found in $[14,15,39]$ ), but it is also necessary to be aware of certain conditions.

First, it is important to build trust with the child and to make preparations for planning the qualitative research with the child. This includes an information letter targeting each specific child to ensure common expectations for the interview between the researcher and the child as well as to give the child an idea about the possible scenarios in an interview. For a child with autism, it may be difficult to imagine what a conversation with a stranger will entail, and the child will often need guidance beforehand. In this study, we have experienced the potential pitfall of "preparing the child too much," that is, not leaving room for a more spontaneous dialogue, while receiving requests from both parents and children for detailed preparation.

Second, preparation concerns the researcher's readiness for more deviant communication forms, methods, and topics. Some examples are having an interview while the child is doing puzzles or spinning around in a chair, communicating without eye contact or proper mimicry, as well as being prepared to communicate around computer games and Japanese manga comics. In this study, we have experienced how difficult it can be to read and interpret the body language of a child with autism during the interview as well as for the child to read the interviewer's body language and spoken hints about shifting conversational topics. Important findings include the need to avoid interpreting the body language of a child with autism based on general assumptions about bodily communication and to be very explicit as a researcher in the communication with the child.

Furthermore, this study has shown that it might be beneficial to begin with precise and limited questions, specifically addressing the conditions that are relevant to the child and thereby clarifying the researcher's intentions regarding the communication. Similar to Teachman and Gibson's [27] findings from their qualitative interview study involving another minority group of children with health conditions (see also [47]), we have found it optimal to combine approaches, such as asking more detailed and close-ended questions to begin with and then posing more open-ended questions when the child has "warmed up." Each interview or conversation should be customized. For instance, if picture cards or other visual materials are used in an interview, they should be well known to the child, resembling those used in his or her school class or at home; otherwise, the pictures could confuse the child.

Such learnings and shared experiences might be useful when conducting qualitative research involving children in general, some of whom require extra guidance and precision as well as preparation and detailed explanations. However, this need is even greater for children with autism, as they often have difficulty imagining situations that they have not yet experienced as well as understanding unwritten rules and assumptions about proper communication form and detail orientations. More research is called for in order to gain more generalizable knowledge upon conducting qualitative research with children with autism, and how it differs from qualitative research with children in general. 
The fact that children with autism possess mindsets and modes of expression that, in many aspects, differ completely from those of the researcher who interacts with them places great demands on the researcher to set aside any presumptions about communication and social interaction in the interviews and conversations. Developing rapport with a child with autism might take time and requires the researcher to become familiar with the individual child, for example, regarding specific autism symptoms, special interests, or any particular challenges in everyday life that could be addressed appropriately. Furthermore, methods allowing the researcher to develop rapport with the child over time are preferable to one-time conversations with the child. Reviewing the field of childhood studies and methods concerning the involvement of children with autism reveals that this group's voice remains under-represented in the literature. For this reason, this study calls attention to sharing experiences and practices in this field.

Author Contributions: P.S.R. conceived and designed the study with assistance from A.K.P.; P.S.R. conducted the interviews and informal conversations with the children, supervised by A.K.P.; P.S.R. conducted the data analysis with assistance from A.K.P.; and P.S.R. wrote the main part of the paper, A.K.P. wrote parts of the paper and edited together with P.S.R.

Funding: This work was supported by The Danish Council for Independent Research - Social Sciences (DFF 4091-00064) and VIVE - The Danish Center for Social Science Research.

Acknowledgments: We are deeply grateful to all of the children who participated in this qualitative study, without whom this research could not have been achieved. Further, we would like to thank Inge Kryger Pedersen, Department of Sociology, University of Copenhagen, for her valuable comments and support throughout the study process.

Conflicts of Interest: The authors declare no conflict of interest.

\section{References}

1. Alderson, P. Young children's human rights: A sociological analysis. Int. J. Child. Rights 2012, 20, 177-198.

2. Howe, R.B.; Covell, K. Engaging children in citizenship education: A children's rights perspective. J. Educ. Thought 2009, 43, 21-44.

3. Ross, H. Adults as grown-up children-A perspective on children's rights. Aust. J. Fam. Law 2013, 27, 235-261.

4. Wyness, M. Childhood and Society. In An Introduction to the Sociology of Childhood; Palgrave Macmillan: New York, NY, USA, 2006.

5. Boyden, P.; Muniz, M.; Laxton-Kane, M. Listening to the views of children with learning disabilities: An evaluation of a learning disability CAMHS service. J. Intellect. Disabil. 2013, 17, 51-63.

6. Brady, G.; Lowe, P.; Lauritzen, S.O. Connecting a sociology of childhood perspective with the study of child health, illness and wellbeing: Introduction. Sociol. Health Illn. 2015, 37, 173-183.

7. Mayall, B. Towards a Sociology for Childhood: Thinking from Children's Lives; Open University Press: Buckingham, UK, 2002.

8. Ulvik, O.S.; Gulbrandsen, L.M. Exploring children's everyday life: An examination of professional practices. Nord. Psychol. 2015, 67, 210-224.

9. Docherty, S.; Sandelowski, M. Focus on qualitative methods: Interviewing children. Res. Nurs. Health 1999, 22, 177-185. [PubMed]

10. Kirk, S. Methodological and ethical issues in conducting qualitative research with children and young people: A literature review. Int. J. Nurs. Stud. 2007, 44, 1250-1260.

11. Hedegaard, M.; Aronsson, K.; Højholt, C.; Ulvik, O.S. (Eds.) Children, Childhood, and Everyday Life: Children's Perspective; IAP, Information Age Publishing: Charlotte, NC, USA, 2012.

12. Morgan, M.; Gibbs, S.; Maxwell, K.; Britten, N. Hearing children's voices: Methodological issues in conducting focus groups with children aged 7-11 years. Qual. Res. 2002, 2, 5-20.

13. Centres for Disease Control and Prevention. Prevalence of Autism Spectrum Disorders among Children Aged 8 Years-Autism and Developmental Disabilities Monitoring Network 11 Sites; Centres for Disease Control and Prevention: Atlanta, GA, USA, 2014.

14. Parsons, S. 'Why are we an ignored group?' Mainstream educational experiences and current life satisfaction of adults on the autism spectrum from an online survey. Int. J. Incl. Educ. 2015, 19, 397-421. 
15. Preece, D.; Jordan, R. Obtaining the views of children and young people with autism spectrum disorders about their experience of daily life and social care support. Br. J. Learn. Disabil. 2010, 38, 10-20.

16. Frith, U.; Happe, F. Autism spectrum disorder. Curr. Biol. 2005, 15, R786-R790. [PubMed]

17. Couteur, A.L.; Szatmari, P. Chapter 51 Autism Spectrum Disorder. In Rutter's Child and Adolescent Psychiatry, 6th ed.; Thaper, A., Pine, D.S., Leckman, J.F., Scott, S., Snowling, M.J., Taylor, E., Eds.; Wiley Blackwell: Oxford, UK, 2015; pp. 665-682.

18. Baron-Cohen, S. Theory of mind and autism: A review. Autism 2000, 23, 169-184.

19. Howlin, P.; Mawhood, L.; Rutter, M. Autism and developmental receptive language disorder-a follow-up comparison in early adult life. II: Social, behavioural, and psychiatric outcomes. J. Child Psychol. Psychiatry 2000, 41, 561-578. [PubMed]

20. Cederlund, M.; Hagberg, B.; Billstedt, E.; Gillberg, I.; Gillberg, C. Asperger syndrome and autism: A comparative longitudinal follow-up study more than 5 years after original diagnosis. J. Autism Dev. Disord. 2008, 38, 72-85.

21. Billstedt, E.; Gillberg, C.; Gillberg, C. Autism after adolescence: Population-based 13- to 22-year follow-up study of 120 individuals with autism diagnosed in childhood. J. Autism Dev. Disord. 2005, 35, 351-360.

22. Goodley, D.; Lawthom, R.; Runswick-Cole, K. Disability and austerity: Beyond work and slow death. Disabil. Soc. 2014, 29, 980-984.

23. Hacking, I. Humans, Aliens \& Autism. Daedalus 2009, 138, 44-59.

24. Smith, J.C. The embodied becoming of autism and childhood: A storytelling methodology. Disabil. Soc. 2016, 31, 180-191.

25. Irwin, L.G.; Johnson, J. Interviewing young children: Explicating our practices and dilemmas. Qual. Health Res. 2005, 15, 821-831.

26. Darbyshire, P.; MacDougall, C.; Schiller, W. Multiple methods in qualitative research with children: More insight or just more? Qual. Res. 2005, 5, 417-436. [CrossRef]

27. Teachman, G.; Gibson, B.E. Children and youth with disabilities: Innovative methods for single qualitative interview. Qual Health Res. 2013, 23, 264-274. [CrossRef] [PubMed]

28. Christians, C. Ethics and politics in qualitative research. In Handbook of Qualitative Research, 2nd ed.; Denzin, N.K., Ed.; SAGE: Thousand Oaks, CA, USA, 2000; pp. 133-162.

29. Bengtsson, T.T.; Fynbo, L. Analysing the significance of silence in qualitative interviewing: Questioning and shifting power relations. Qual. Res. 2018, 18, 19-35.

30. Samuelsson, I.P.; Pramling, N. Children's perspectives as 'touch downs' in time: Assessing and developing children's understanding simultaneously. Early Child Dev. Care 2009, 179, 205-216. [CrossRef]

31. Piaget, J. The Child's Concept of the World; Routledge: London, UK, 1929.

32. Qvortrup, J. The Sociology of Childhood by William, A. Corsaro. Book Review. Child. Soc. 1998, 12, 318-321. [CrossRef]

33. Sommer, D.; Samuelsson, I.P.; Hundeide, K. Child Perspectives and Children's Perspectives in Theory and Practice; Springer Science and Business Media LLC: London, UK, 2010.

34. Prout, A. The Body, Childhood and Society; MacMillan Press LTD: London, UK, 2000.

35. Hammersly, M.; Atkinsons, P. Ethnography, Principles in Practice, 3rd ed.; Routledge: New York, USA, 2007.

36. Tulebaeva, B. Revisiting ethics in ethnographic research with children. Orient. Anthr. A Bi-Annu. Int. J. Sci. Man 2014, 14, 203-216. [CrossRef]

37. Christensen, P.H. Children's participation in ethnographic research: Issues of power and representation. Child. Soc. 2004, 18, 165-176. [CrossRef]

38. Lewis, A.; Lindsay, G. (Eds.) Researching Children's Perspectives; Open University Press: Buckingham, UK, 2000.

39. Einarsdottir, J.; Egilson, S.T. Chapter 3. Embracing diversity in childhood studies: Methodological and practical considerations. In Diversity in the Early Years, Intercultural Learning and Teaching; Farrell, A., Samuelsson, I.P., Eds.; Oxford University Press: Melbourne, Australia, 2016; pp. 35-53.

40. Smith, J.A. Interpretative phenomenological analysis: Getting at lived experience. J. Posit. Psychol. 2016, 12, 303-304. [CrossRef]

41. Smith, J.A.; Flower, P.; Larkin, M. Interpretative Phenomenological Analysis: Theory, Method and Research; Sage: London, UK, 2009. 
42. Smith, J.A.; Osborn, M. Interpretative Phenomenological Analysis. In Qualitative Psychology, A Practical Guide to Research Methods; Smith, J.A., Ed.; SAGE Press: London, UK, 2007.

43. Jacobsson, K.; Åkerström, M. Interviewees with an agenda: Learning from a 'failed' interview. Qual. Res. 2013, 13, 717-734. [CrossRef]

44. Greig, A.; Taylor, J. Doing Research with Children; Sage: London, UK, 1999.

45. Wilson, C.; Powel, M. A Guide to Interviewing Children: Essential Skills for Councellors, Police, Lawyers and Social Workers; Routledge: New York, NY, USA, 2001.

46. Pramling, I. Learning to Learn: A Study of Swedish Preschool Children; University Press: New York, USA, 1990.

47. Woodgate, R. Adopting the qualitative paradigm to understanding children's perspectives of illness: Barrier or facilitator? J. Pediatr. Nurs. 2001, 16, 149-161. [CrossRef]

48. Steward, M.S.; Steward, D.S. Interviewing young children about body touch and handling. Monogr. Soc. Res. Child Dev. 1996, 61, 1-186. [CrossRef] [PubMed]

49. Tissot, C.; Evans, R. Visual teaching strategies for children with autism. Early Child Dev. Care 2003, 173, 425-433. [CrossRef]

(C) 2019 by the authors. Licensee MDPI, Basel, Switzerland. This article is an open access article distributed under the terms and conditions of the Creative Commons Attribution (CC BY) license (http://creativecommons.org/licenses/by/4.0/). 